\title{
Analysing the effects of working period on psychophysiological states of seafarers
}

\author{
Barış Özsever ${ }^{1}$, Leyla Tavacıoğlu \\ ${ }^{1}$ Maritime Faculty, Piri Reis University, Istanbul, Turkey \\ ${ }^{2}$ Maritime Faculty, Istanbul Technical University, Istanbul, Turkey
}

\begin{abstract}
Background: Human factor has become a critical issue due to the fact that all operational processes in maritime transportation have been accelerated with technological innovations. Irregular and long working hours, rapid change of working environments and other organisational and/or individual factors have negative impact on the performance of the seafarers as well as other transportation workers and/or shift workers. Seafarers working under the influence of these stressor factors, naturally, are affected from psychophysiological and cognitive aspects, which in return decrease their overall performances. The study mainly aimed to investigate which of the above mentioned affecting factors had greater impact on seafarers' performances. Materials and methods: For this purpose, data for 14 healthy male seafarers on board different vessels was collected. The collected data included the number of port visits, frequency of change of circadian rhythm, total working hours and watchkeeping periods in the recent month. In order to analyse the psychophysiological effect of working period, electrodermal activity and heart rate variability measurements for arousal mood and data from 2-choice reaction time tests for cognitive performance were collected from the seafarers.

Results: Obtained data was analysed in SPSS software programme applying multiple regression with factor analysis to model the dependence between psychophysiological states of seafarers and working periods. Conclusions: According to the results, it was determined that the change of circadian rhythm is the main determinant factor for seafarers. The results showed that when seafarer's circadian rhythm is changed more frequently, they experience more drowsiness.
\end{abstract}

(Int Marit Health 2018; 69, 2: 84-93)

Key words: seafarer, human factor, circadian rhythm, psychophysiology, working hours

\section{INTRODUCTION}

Human factor became a more critical issue with the acceleration of all operational processes in maritime transportation. This acceleration causes directly or indirectly decreased port stays, short sailing periods between ports, in other words time pressure, fewer crew on board and long-lasting sleeplessness periods. In early studies, it has been clearly stated that irregular and long working hours have negative effects on physical, emotional and mental fatigue. Grandjean [1] emphasised that fatigue can not only be comprehended as a physical fact but also as a mental fact which is one of the most important causes of incidents and injuries. It has also been indicated that shift work system and long working hours have caused serious psychophysiological effects on workers [2-8]. In the light of their studies, sleeplessness and excessive workload have not only caused fatigue in workers, but also affected them cognitively which in turn decrease their overall performances. Long working hours, as a parameter of working period, are one of the most important factors that cause fatigue and drowsiness [9-12]. Rengamani and Murugan [13] indicated that International Convention on Standards of Training, Certification and Watchkeeping for Seafarers (STCW) regulation, which says "seafarers have to rest 10 hours minimum in a day", allows long working hours. Minimum rest periods for seafarers, as mentioned on STCW, does not correspond especially with vessels making frequent port visits. In addition to long working 
hours, the shift work system is another main cause of fatigue [11, 14-17].

Recent studies on the topics of fatigue, stress and emotional states have been focused on biometrical measurements to detect fatigue or emotional states [18-20]. Sharma and Gedeon [21] mainly classified the measurements and computational techniques for stress recognition. They specified that the biometrical measurements such as electrodermal activity (EDA), heart rate variability (HRV), brain activity could be modelled by computational techniques such as Bayesian classification, artificial neural networks etc. for stress recognition. Additionally, authors focused on the statistical predictions of emotional states by psychophysiological signals [22, 23]. Chueh et al. [24] tested the statistical methods on measured physiological signals to develop emotion recognition system and they found that regression analysis and MANOVA could significantly improve the system. The multivariate statistical techniques such as multivariate regression, factor analysis, and multivariate variance analysis have been implemented to lots of psychophysiological research cases.

In this context, this study aims to analyse the effects of working period on seafarers and develop the statistical prediction of psychophysiological effects arising from working period. In order to analyse the psychophysiological effect of working period; EDA and HRV measurements for arousal mood and data from 2-choice reaction time tests for cognitive performance were collected from the seafarers. The figures were collected during the port period on board different container vessels both at the beginning and at the end of the cargo watches. Also, working period data of seafarers were collected. The collected data include the number of port visits, frequency of change of circadian rhythm, total working hours and watchkeeping periods in the recent month. All data were analysed in SPSS software programme applying multiple regression with factor analysis to model the dependence between psychophysiological states of seafarers and working periods.

\section{RELATED WORK}

Shift work and frequent port visits can cause seafarers to work for long hours. In early studies, long working hours has been found as the main risk factor of maritime accidents $[25,26]$. Accordingly, following parts of this chapter include the factors that cause cognitive and psychophysiological defects, the findings and suggestions on this issue.

\section{FINDINGS IN MARITIME DOMAIN}

Numerous studies show that shift work system is one of the key parameters for fatigue $[11,15,16]$. When watch schedules change, total actual sleep durations of seafarers decrease compared to seafarers who have fixed watch schedules [27]. Due to this change, the seafarers with a fixed watch schedule were found to be more rested than those without. Awareness and attention decrease along with sleeplessness and fatigue [28-30]. Besides, watchkeeping officers tend to fall asleep at the end of the watch, mostly between 00:00 and 06:00. Working/resting hours and mealtimes are disrupted due to change of circadian rhythm of seafarers and their awareness and vitality are affected by shift work [10, 31]. These results show that changing of sleep period and circadian rhythm highly affects cognitive abilities and psychophysiological states of seafarers.

Decreased port stays and short sailing periods between ports have caused fatigue in seafarers [11, 32]. Having small number of crew on board as well as short sailing periods between ports is a significant reason of fatigue in seafarers $[13,33]$.

Long working hours is one of the most significant factors generating fatigue and sleeplessness [9, 10, 12, 34]. The STCW regulation allows long working hours especially for vessels which make frequent port visits by putting into words as "seafarers have to rest 10 hours minimum in a day". Frequent port visit has negative effect on ratings due to difference of the tasks and watch schedules in ports and at sea [13].

Examining the reasons of the accidents that occurred between 1991 and 2000, Phillips [35] indicated that 39\% was related to sleep/falling asleep, but very few of them were related to fatigue. Indeed, working in low alertness atmosphere could cause acute fatigue [10]. Its symptoms can appear as drowsiness and lack of attention.

All crew who works in small bulk carriers and container ships which make coastal navigation, is getting more tired in comparison with other type of vessels [36-39]. On the other hand, ratings experience more injuries related to fatigue or lack of attention than officers [40, 41]. Therefore, vessel type and seafarer's rank are determinative for fatigue.

\section{DEVELOPMENTS IN FATIGUE DETECTION}

Researchers have worked on development of fatigue detection systems. Many detailed literature data are available about research on fatigue detection in drivers, pilots and astronauts. In one of these researches, multiple regression analysis of electroencephalography (EEG) data, was used to detect driver fatigue and to develop a fatigue countermeasure device [5]. Fatigue and anxiety were related to each other in fatigue detection. Similarly, to detect vigilance of pilots, EDA and HRV were combined and an algorithm was created for assessment of the adaptation to task demands [42]. Collecting EEG and electrooculography (EOG)_data, the fatigue monitoring system has been developed for astronauts. These data were correlated with psychomotor vigi- 
lance tasks that evaluated the sleepiness of astronauts [43]. Singh et al. [19] successfully implemented the Layer Recurrent Neural Networks for stress level detection on drivers by collecting EDA and photoplethysmogram (PPG)_data. Such computational systems can develop the safety systems to detect fatigue.

The studies which analyse the effects of stressor factors on seafarers are not sufficient but there are even less reports on biometrical measurements. Maurier et al. [28] took measurements from officers and engineers at Horizon Project in a 6 on 6 off shift system with a seven-day navigation process in the bridge, engine room and cargo control room simulators. According to the observations of seafarer behaviours, awareness and attention decreased with fatigue and residence times increased in designated areas. Similarly, sleepiness and fatigue states of watchkeeping officers on vessels, which make coastal navigation, were evaluated by EEG, heart rate and $\mathrm{SpO}_{2}$ measurements in bridge simulator [30]. In respect to the findings, awareness and attention decreased along with sleeplessness and fatigue. Tac et al. [44] observed the effects of temperature, noise and motion on the cognitive abilities of seafarers particularly in engine room. These effects were observed by using EEG and cognitive tests. At the end of the watch, the cognitive ability was decreased and needed brain activity was increased to solve tests.

Although physical, psychological and cognitive researches have been described in literature, modelling cause and effect relationship for fatigue and developments of fatigue/ /stress detection systems were in research phase in maritime domain. Lützhöft and Sri [45] developed a Fatigue Management Tool Kit, and created MARTHA software which is to be used on board. It is a mathematical calculation tool that is to figure out circadian rhythm by entering work/ /rest times. They recommended waiting at least 5-6 days before the change of watch schedules for seafarers' circadian rhythms. The weak side of this software is that only working and resting hour data can be entered. There is no biometrical assessment or actual sleeping times. Yet, it has been stated that sleep quality and actual sleep duration are disturbed due to change of circadian rhythm in previous studies.

\section{MATERIALS AND METHODS}

Fourteen healthy male seafarers participated in the study. All subjects declared having no chronical, neurological or psychiatric illness. Measurements were taken at Ambarlı Port (Istanbul, Turkey) calls of 6 different container ships which have different routes and different working schedules. The study was approved by the Health and Engineering Sciences Human Researches Ethical Committee of Istanbul Technical University.

\section{DATA COLLECTION FOR CIRCADIAN RHYTHM}

A circadian rhythm is a behavioural and physiological 24-hours cycle which is created by one or more internal biological clocks. Circadian rhythm controls the body's sleep/ /wake condition, hormone levels and periodic changes of body temperature in a 24-hour cycle under the influence of these biological clocks. Light is one of the most important factors which affect this cycle. Being apart from light, exercise, social stimulants, nutrition, and heat also affect the circadian rhythm [46]. When the ship's working conditions are considered, change of watchkeeping periods at ports, rotations on watch schedules and working in a light-free environment negatively affect the circadian rhythm of the body.

Working period was described as the number of port visits, the frequency of change of circadian rhythm, total working hours and watchkeeping periods of seafarers. Watchkeeping periods are scheduled as 00:00-04:00 together with 12:00-16:00, 04:00-08:00 together with 16:00-20:00 and 08:00-12:00 together with 20:00-24:00 for seafarers. In this context, work/rest hours schedules that included the detailed manoeuvring times, port durations and other issues for recent month were collected for each participant.

\section{ELECTRODERMAL ACTIVITY MEASUREMENT}

Emotional sweating, also known as galvanic skin response or EDA, which is only affected by the sympathetic nervous system, is one of the stress indicators in the body [47]. Conductivity with increasing tendency of the humidity allows the measurement while individual is stressed. Thus, when the stress increases, the EDA increases. Electrodermal activity has also been correlated with stressors such as mental workload and work performance [48]. The stress levels were classified as relaxed, moderate, and stressful by measuring the EDA to determine drivers' stress levels $[19,49,50]$. The response of eccrine sweat bland, which indicates EDA, was observed in cases of increased attention, increased consciousness, sudden stoppage in understanding, problem solving and anxiety [42].

After the vessels were alongside and the cargo operations were commenced, the activation levels of body and the arousal states of seafarers were observed in operation process by taking EDA measurements at the beginning and at the end of the watches for 10 minutes. Electrodermal activity was measured according to the skin conductivity between 0.5 microsiemens ( $\mu S$ ) and $20 \mu S$ by two aluminium electrodes with the measurement device presented in Figure 1.

\section{HEART RATE VARIABILITY MEASUREMENT}

Heart rate variability is a stress indicator. It also shows how individual adapts to changes. HRV is an increase or decrease in heart rate relative to normal heart rate. For 

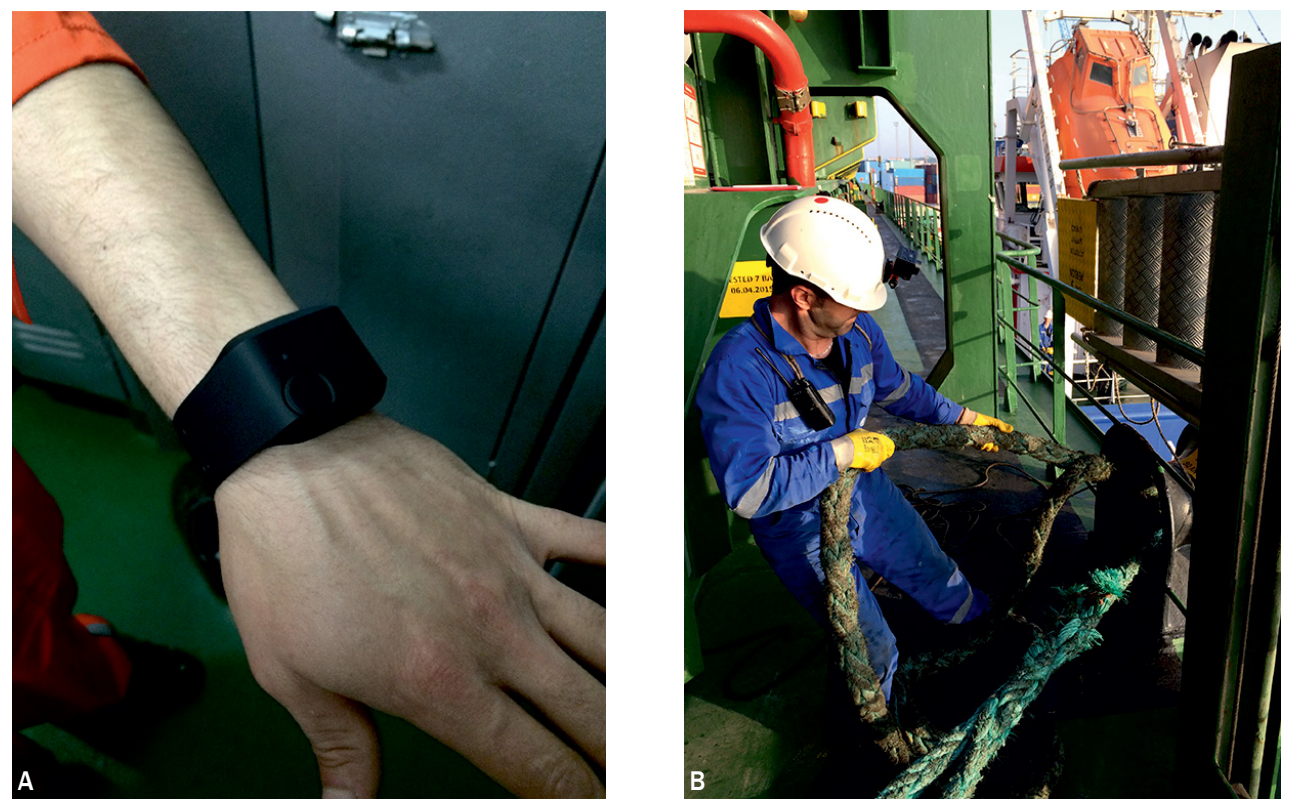

Figure 1. A. Electrodermal activity measurement device; B. Data collection in operation process

example, an average of 60 heartbeats per minute does not mean that it beats once per second. The heart rate is between 0.5 and 2 seconds. However, stress is determined according to the parameters based on frequency rather than those based on time. The fluctuations in the heart rate are resolved into numerical powers within certain frequencies. The low-frequency to high-frequency (LF/HF) ratio is an evaluation parameter and shows a sympathetic-parasympathetic balance. Increase in rate means the sympathetic activation while decrease in rate means the parasympathetic activation [51]. Adding to their specifications, the synchronisation of EDA and HRV shows the arousal and activation state [52]. EDA and HRV were used together to detect the vigilance or activation states of pilots, seafarers and automotive drivers [3, 19, 42].

The HRVs of seafarers were monitored simultaneously with EDA in the study. Heart rate variability was measured with the aid of plastic electrodes on the belt with the measurement device presented in Figure 2.

\section{TWO-CHOICE REACTION TIME TEST}

The reaction time refers to the duration from the activation of stimulation until the response to stimulation. The reaction time is divided into a simple stimulus versus a simple reaction time for which simple movement is expected and an optional reaction time at which desired movement is expected according to the type of stimulus [53]. According to Madden [54], the reaction time is a measure of the data processing speed of the central nervous system. When it is evaluated in terms of long working hours and the resulting lack
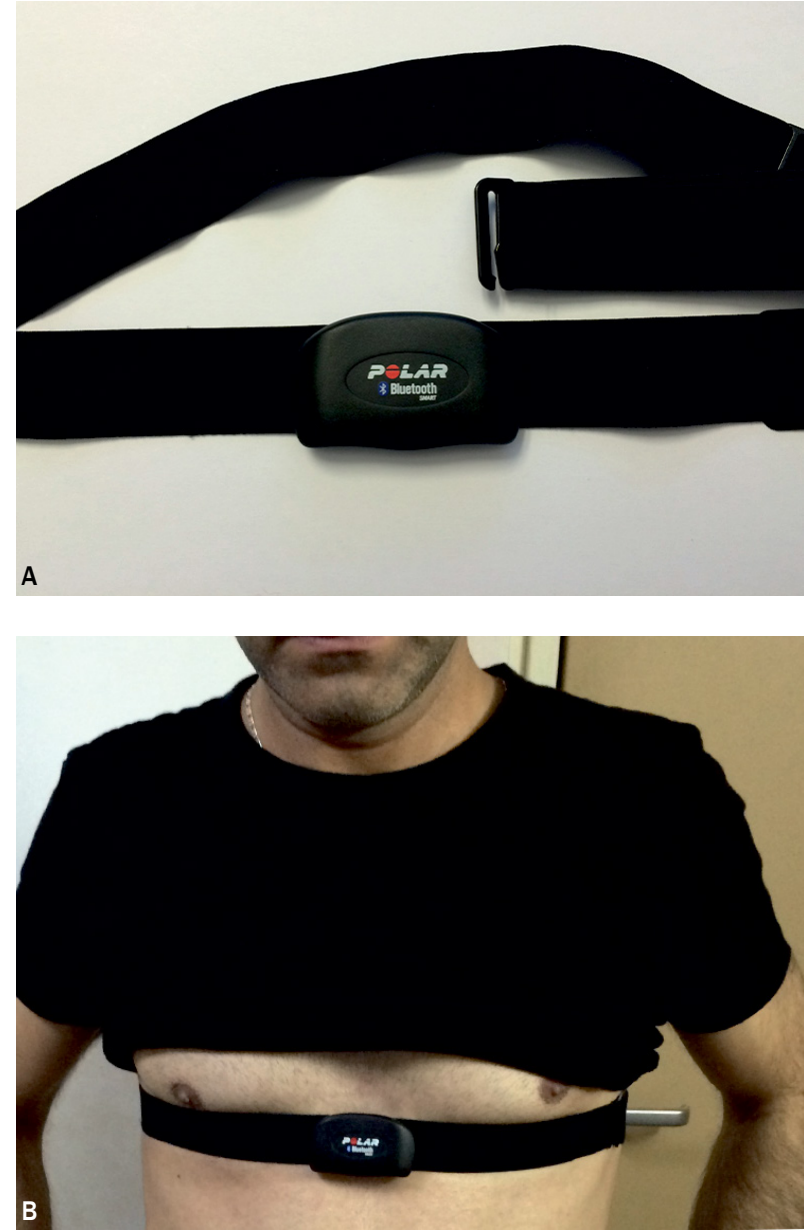

Figure 2. A. Heart rate variability measurement device; B. The use of the device 
of sleep, it is stated that sleep deprivation leads to a reduction of about 50\% in learning cognitive and procedural knowledge [55].

In this study, the 2-Choice Reaction Time evaluation test of Automated Neuropsychological Assessment Metrics (ANAM) Version 4 was used to evaluate the cognitive performance of the seafarers. This evaluation test was performed by a seafarer before he/she commenced the watch and after he/she completed the watch. In this respect, it allowed observation on the change in reaction time of the seafarer during the port operation.

\section{MULTIVARIATE ANALYSIS}

Dependent and independent variables were determined to model the dependence between psychophysiological states of seafarers and working period. Due to the fact that the model consists on the effect of working period on psychophysiological states of seafarers, dependent variables are the psychophysiological measurements consisting of EDA, HRV and reaction time. Correspondingly, independent variables are the number of port visits, the frequency of change of circadian rhythm, total working hours and the watchkeeping periods of seafarers.

The correlation between EDA values and HRV values ( $) 1 \mathrm{y} 2=0.505$ ) confirms the Thayer's [52] model of synchronisation; these two measurements indicate activation states or arousal moods of individual. Besides, there are high correlations between EDA and reaction time values ( $\rho 1 \mathrm{y} 3=-0.650)$ and between HRV and reaction time values $(\rho \mathrm{y} 2 \mathrm{y} 3=-0.534)$. They point out that when EDA and HRV (arousal mood) of seafarer decrease, reaction time prolongs. Therefore, factor analysis is implemented to dependent variable for regression analysis. Factor analysis is a technique used to reduce a great number of variables, considered to be related to each other, to fewer irrelevant basic dimensions (factors) by examining the relationship between them [56]. In this context, Figure 3 represents the structural model of factor analysis for this study.

After factor analysis, regression analysis is implemented to analyse the effects of independent variables, which are the number of port visits, the frequency of change of circadian rhythm and total working hours of seafarers, on dependent variable. Regression analysis is used for predicting values of one or more dependent variables from an addition of independent variable values [57]. In this context, regression analysis has the following form:

$$
Y_{\text {Drowsiness }}=\beta_{0}+\beta_{1} X_{1}+\beta_{2} X_{2}+\beta_{3} X_{3}+\varepsilon
$$

where $\beta$ i are the coefficients of independent variables, $\varepsilon$ is random error and $X_{1}, X_{2}, X_{3}$ are respectively the number of port visits, the frequency of change of circadian rhythm and the total working hours of seafarers. All values and variables

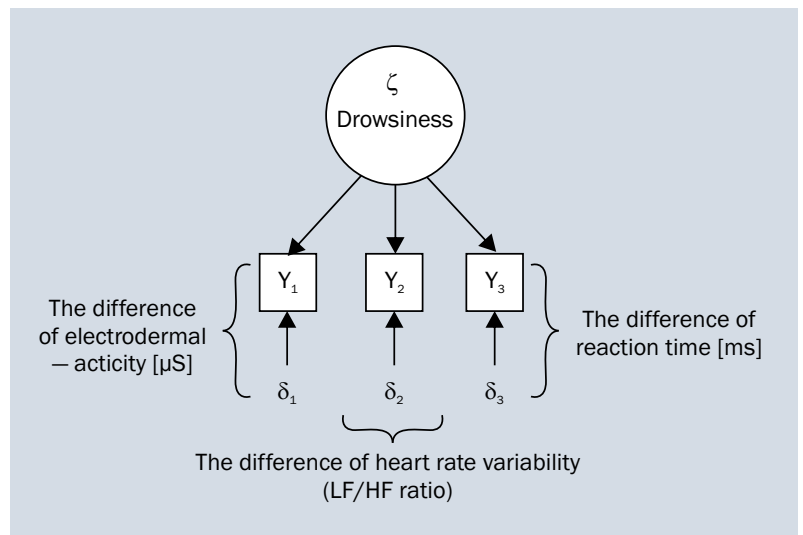

Figure 3. A structural model for factor analysis representing the dependent variablesl; LF/HF - low-frequency/high frequency

were statistically analysed in SPSS (Statistical Package for Social Sciences) programme.

\section{RESULTS}

\section{EXPERIMENTAL RESULTS}

According to the measurements, there were differences between the values at the beginning of the watch and those at the end of the watch. Figure 4 represents the difference of the values for one participant. There can be seen an increase in arousal mood and activation state of seafarer at the beginning of the watch. However, the needed level of activation did not occur at the end of the watch. The participant showed lower activation for the same work at the end of the watch. There is also a synchronization of EDA and HRV which occurs after 180 seconds.

After obtaining the experiment results, statistical analysis was carried out in order to assess which working period variables were determinative in changes of psychophysiological states.

\section{STATISTICAL ANALYSIS}

First of all, MANOVA was carried out in order to analyse the effect of watchkeeping period to psychophysiological states of seafarers in SPSS programme. Box's test of equality of covariance matrices (Table 1) and Levene's test of equality of error variances (Table 2) was carried out for applicability of multivariate analysis.

Even though the multivariate analysis is applicable for these data, none of the watchkeeping periods affected the psychophysiological states of seafarers (the value of Wilks' Lambda $=0.486$; $\operatorname{sig}=0.306, p<0.05$ ).

Secondly, factor analysis (presented in Figure 3) was carried out to reach one dependent variable represented as drowsiness. Table 3 is the correlation matrix that shows the correlation among the dependent variables. According 


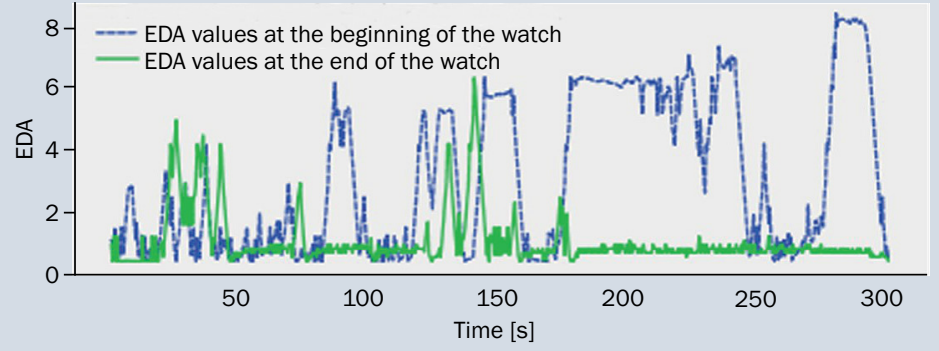

B

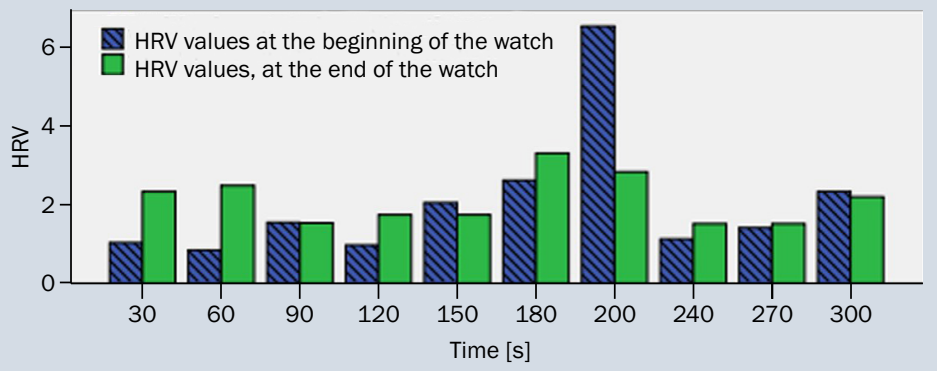

Figure 4. The change of electrodermal activity (EDA) (A) and heart rate variability (HRV) (low-frequency to high-frequency [LF/HF] ratio); (B) values of one participant during the watch

Table 1. Box's test of equality of covariance matrices

$\begin{array}{lc}\text { Box's M } & 7.158 \\ \text { F } & 0.328 \\ \text { df1 } & 12 \\ \text { df2 } & 399.296 \\ \text { Sig. } & 0.984\end{array}$

to this, EDA and HRV (stated in Table 3 as LF/HF diff.) are positively correlated which indicates the parallel effect from sympathetic-parasympathetic nervous system. Besides, EDA and reaction time (stated in Table 3 as RTt diff.) have negatively correlated. So, it means the decrease of EDA activity is the increase in reaction time of given response to 1 case. This result indicates that cognitive ability can

Table 2. Levene's test of equality of error variances

\begin{tabular}{lllll}
\hline & F & df1 & df2 & Sig. \\
\hline EDA diff. & 0.860 & 2 & 11 & 0.450 \\
RTt diff. & 0.929 & 2 & 11 & 0.424 \\
LF/HF diff. & 0.846 & 2 & 11 & 0.455
\end{tabular}

EDA - electrodermal activity; RTt - reaction time; LF/HF - low frequency to high frequency; diff. - the differences of the psychophysiological states between beginning of the watch and end of the watch of participants

Table 3. Correlation matrix

\begin{tabular}{lllll}
\hline & & EDA diff. & RTt diff. & LF/HF diff. \\
\hline Correlation & EDA diff. & 1.000 & 0. & 0.505 \\
& RTt diff. & -0.650 & 1.000 & -0.534 \\
Sig. (1-tailed) & LF/HF diff. & 0.505 & -0.534 & 1.000 \\
& EDA diff. & & 0.006 & 0.033 \\
& RTt diff. & 0.006 & & 0.025
\end{tabular}


be affected by autonomic nervous system. The outcome conforms to the previous studies in existing literature which argues that sleeplessness, change of circadian rhythm and fatigue have a negative impact on individual's reaction time $[17,55,58]$.

Table 4 represents the applicability of factor analysis to these dependent variables ( $\mathrm{sig}=0.014, \mathrm{p}<0.05$ ).

Table 5 represents the total variance explained by the component which is formed via factor analysis. According to analysis presented in Table 5, the component explains $70.96 \%$ of total variance for dependent variables.

Table 4. Kaiser-Meyer-Olkin and Bartlett's test

$\begin{array}{ll}\text { Kaiser-Meyer-Olkin measure of sampling adequacy } & 0.691 \\ \text { Bartlett's test of sphericity: } & \\ \text { Approx. Chi-Square } & 10.581 \\ \text { df } & 3 \\ \text { Sig. } & 0.014\end{array}$

Finally, regression analysis was implemented to mathematically examine the effects of the working period's variables. Table 6 represents the descriptive statistics of working period's variables.

The regression model (presented in Table 7) can explain moderately the relationship between working period and the psychophysiological states of seafarers (R square $=0.646$, adjusted $\mathrm{R}$ square $=0.540$ ). Table 8 represents the significance of regression model with ANOVA ( $\operatorname{sig}=0.013, p<0.05$ ).

The coefficients of working period's variables are needed to state in regression formula (1) to examine the effects of working period's variables on psychophysiological states of seafarers. These coefficients of independent variables are presented in Table 9.

According to the coefficients and their significance values, the significant factor is only the frequency of change of circadian rhythm from working period's variables (sig $=0.002$, $p<0.05)$. Other variables have lower impact and significance on the psychophysiological states of seafarers. Regression formula can be stated with final coefficients as follows:

Table 5. Total variance explained

\begin{tabular}{|c|c|c|c|c|c|c|}
\hline \multirow[t]{2}{*}{ Component } & \multicolumn{3}{|c|}{ Initial eigenvalues } & \multicolumn{3}{|c|}{ Extraction sums of squared loadings } \\
\hline & Total & $\%$ of variance & Cumulative \% & Total & $\%$ of variance & Cumulative $\%$ \\
\hline 1 & 2.129 & 70.960 & 70.960 & 2.129 & 70.960 & 70.960 \\
\hline 2 & 0.523 & 17.433 & 88.392 & & & \\
\hline 3 & 0.348 & 11.608 & 100.000 & & & \\
\hline
\end{tabular}

Extraction method: principal component analysis.

Table 6. The descriptive statistics of working period's variables

\begin{tabular}{llll}
\hline & Mean & Standard deviation & N \\
\hline Number of port visits & 11.57 & 3.435 & 14 \\
Frequency of change of circadian rhythm & 5,36 & 4.634 & 14 \\
Total working hours & 240.79 & 10.297 & 14
\end{tabular}

Table 7. Regression model summary

\begin{tabular}{|c|c|c|c|c|c|c|c|c|c|c|}
\hline \multirow[t]{2}{*}{ Model } & \multirow[t]{2}{*}{$\mathbf{R}$} & \multirow[t]{2}{*}{ R square } & \multirow{2}{*}{$\begin{array}{l}\text { Adjusted } \\
\text { R square }\end{array}$} & \multirow{2}{*}{$\begin{array}{l}\text { Standard } \\
\text { error of the } \\
\text { estimate }\end{array}$} & \multicolumn{5}{|c|}{ Change statistics } & \multirow[t]{2}{*}{ Durbin-Watson } \\
\hline & & & & & $\begin{array}{l}\text { R square } \\
\text { change }\end{array}$ & F change & df1 & df2 & $\begin{array}{l}\text { Sig. F } \\
\text { change }\end{array}$ & \\
\hline 1 & 0.804 & 0.646 & 0.540 & 0.7850343 & 0.646 & 6.079 & 3 & 10 & 0.013 & 1.834 \\
\hline
\end{tabular}

Table 8. ANOVA

\begin{tabular}{|c|c|c|c|c|c|}
\hline Model 1 & Sum of squares & df & Mean square & $\mathbf{F}$ & Sig. \\
\hline Regression & 8.396 & 3 & 2.799 & 6.079 & $0.013^{*}$ \\
\hline Residual & 4.604 & 10 & 0.460 & & \\
\hline Total & 13.000 & 13 & & & \\
\hline
\end{tabular}

*Predictions: (Constant), total working hours, frequency of change circadian rhythm, number of port visits. 
Table 9. The coefficients of working period's variables

\begin{tabular}{|c|c|c|c|c|c|}
\hline \multirow[t]{2}{*}{ Model 1} & \multicolumn{2}{|c|}{$\begin{array}{l}\text { Unstandardised } \\
\text { coefficients }\end{array}$} & \multirow{2}{*}{$\begin{array}{l}\text { Standardised } \\
\text { coefficients } \\
\text { Beta }\end{array}$} & \multirow[t]{2}{*}{$\mathbf{t}$} & \multirow[t]{2}{*}{ Sig. } \\
\hline & B & Standard error & & & \\
\hline Constant & 5.535 & 5.812 & & 0.952 & 0.363 \\
\hline Number of port visits & 0.063 & 0.070 & 0.217 & 0.904 & 0.387 \\
\hline Frequency of change of circadian rhythm & 0.193 & 0.048 & 0.895 & 4.039 & 0.002 \\
\hline Total working hours & -0.030 & 0.027 & -0.312 & -1.141 & 0.280 \\
\hline
\end{tabular}

Drowsiness $=5.535+0.63 \times($ number of port visits)

$+0.193 \times$ (frequency of change of circadian rhythm)

$-0.030 \times$ (total working hours)

According to the equation (2), the increase in frequency of change of circadian rhythm for seafarers causes more drowsiness during their cargo watches. In this study, the working period's variables, except the frequency of change of circadian rhythm, have no impact or very low impact on their psychophysiological states. It can be said that the change of circadian rhythm is the main determinant factor of drowsiness of a seafarer. When seafarer's circadian rhythm changes more frequently, he/she experiences more drowsiness.

The findings of the other studies on shift work system are similar that it causes more sleeplessness, lower vigilance and more fatigue for seafarers [11, 14-17]. Besides, authors stated that circadian rhythm is the most significant factor in fatigue, which is consistent with the findings of this study $[10,31,58]$. On the other hand, short sailing periods between ports and long working hours have negative effects on seafarers $[11,59,60]$. However, the number of port visits and total working hours had lower impact on psychophysiological states of seafarers in this study. The differences of the psychophysiological states between beginning of the watch and end of the watch of participants, who have experienced more port visits but less change of circadian rhythm, was not greater than the others. These findings is in line with the findings of Arulanandam and Tsing [27] that seafarers who have fixed watch schedule, both in ports and at sea, experience less fatigue than the others.

\section{CONCLUSIONS}

The study attempted to make a comprehensive research on the working periods of the seafarers who work on shift system. Although negative effects of shift work system have been known in maritime transportation area, empirical studies are still not sufficient to determine what factors are more appropriate to measure the negative effects. The recent data on the subject has shown that ratings as much as officers make mistakes during cargo operations because of the factors such as long working hours, decreased port stays, short sailing periods between ports, time pressure, having small number of crew on board, long-lasting sleeplessness periods and finally because of fatigue. This study focused on the root cause of drowsiness taking ratings' working periods as the main input. Moreover, this study attempted to make a humble contribution to the existing literature on the following issues: In order to assess individual's arousal mood and activation state, synchronization of EDA and HRV can be effectively used; statistical prediction of psychophysiological data is also applicable to assess overall state of an individual. The correlation between reaction time and EDA/HRV is an important indication that shows cognitive ability is affected by autonomic nervous system. This outcome conforms to the previous studies in the existing literature which argues that sleeplessness, change of circadian rhythm and fatigue have a negative impact on individual's reaction time.

The study showed that watchkeeping periods didn't affect the psychophysiological states of seafarers. Besides, the number of port visits and total working hours had lower impact on the psychophysiological states of seafarers. However, the frequency of change of circadian rhythm caused a substantial difference in the psychophysiological states of seafarers. When seafarer's circadian rhythm is changed more frequently, they experience more drowsiness. Actually, an increase in the number of port visits means an increase in the frequency of change of circadian rhythm, especially for ratings due to the fact that ratings normally work on 08:00-17:00 watch schedule at sea but they turn to work on shift work system at ports. Within the course of this study, the frequency of change of circadian rhythm was not high even when the number of port visits was increased. The main reason of this outcome was that the above mentioned daily work schedules were not used by captains of some vessels involved in this study. Thus, the drowsiness of seafarers on these vessels was not observed as much as that of the others.

In the light of the above findings, keeping the number of changes for watchkeeping periods low and making the watchkeeping periods the same both at sea and at ports 
can be a preventive measure to avoid maritime casualties even if the number of port visits is high.

For future researches, in order to develop fatigue detection systems for maritime transportation working environment, it is advisable to have more enhanced empirical studies with a larger group of seafarers. More computational techniques and algorithms including more biometrical measurements will contribute to understanding of the shortcomings and also lead way to overcome the problems.

\section{ACKNOWLEDGEMENTS}

The authors acknowledge with grateful thanks the cooperation of ARKAS Holding for making possible and coordinating measurements on their vessels. The authors are also thankful to Asst. Prof. Aydın Şıhmantepe and their dearest colleague Ece Ceylani for their valuable contributions.

\section{REFERENCES}

1. Grandjean E. Fatigue in industry. Occupational and Environmental Medicine. 1979; 36(3): 175-186, doi: 10.1136/oem.36.3.175.

2. Brown ID. Driver fatigue. Hum Factors. 1994; 36(2): 298-314, doi: 10.1177/001872089403600210, indexed in Pubmed: 8070794.

3. Cook TC, Shipley P. Human factors studies of the working hours of UK ship's pilots. 1. A field study of fatigue. Appl Ergon. 1980; 11(2): 85-92, indexed in Pubmed: 15676378.

4. Gundel A, Marsalek K, Radu C. Sleep-related and time-of-day variations in fatigue and psychomotor performance. Somnologie - Schlafforschung und Schlafmedizin. 2007; 11(3): 186-191, doi: 10.1007/ s11818-007-0305-9.

5. Lal SKL, Craig A. Driver fatigue: electroencephalography and psychological assessment. Psychophysiology. 2002; 39(3): 313-321, doi: 10.1017.S0048577201393095, indexed in Pubmed: 12212650.

6. Ma J, Ma RM, Liu XW, et al. Workload influence on fatigue related psychological and physiological performance changes of aviators. PLoS One. 2014; 9(2): e87121, doi: 10.1371/journal.pone.0087121, indexed in Pubmed: 24505277.

7. Rai B, Foing BH, Kaur J. Working hours, sleep, salivary cortisol, fatigue and neuro-behavior during Mars analog mission: five crews study. Neurosci Lett. 2012; 516(2): 177-181, doi: 10.1016/j. neulet.2012.03.067, indexed in Pubmed: 22487731.

8. Wilson G, Caldwell J, Russell C. Performance and psychophysiological measures of fatigue effects on aviation related tasks of varying difficulty. Int J Aviation Psychology. 2007; 17(2): 219-247, doi: 10.1080/10508410701328839.

9. Allen $\mathrm{P}$, Wadsworth $\mathrm{E}$, Smith $\mathrm{A}$. The prevention and management of seafarers' fatigue: a review. Int Marit Health. 2007; 58(1-4): 167-177, indexed in Pubmed: 18350986.

10. Smith A. A Diary Study of Fatigue Offshore. Contemporary Ergonomics 2008. 2010: 602-606, doi: 10.1201/9780203883259.ch96.

11. Wadsworth EJK, Allen PH, McNamara RL, et al. Fatigue and health in a seafaring population. Occup Med (Lond). 2008; 58(3): 198-204, doi: 10.1093/occmed/kqn008, indexed in Pubmed: 18310605.

12. Xhelilaj $E$, Lapa $K$. The role of human fatigue factor towards maritime casualties. Universitatii Maritime Constanta Analele. 2010; 11(13): 23.

13. Rengamani J, Murugan MSA. study on the factors influencing the seafarers' stress. AMET Int J Management. 2012; 4: 44-51.

14. Hansen JH, Holmen IM. Sleep disturbances among offshore fleet workers: a questionnaire-based survey. Int Marit Health. 2011; 62(2): 123-130, indexed in Pubmed: 21910116.
15. Houtman I, Miedema M, Jettinghoff K, et al. Fatigue in the shipping industry: Hoofddorp: TNO. 2005.

16. Kircher A, Lutzhoft M. editors. Performance of seafarers during extended simulation runs. International Conference on Human Factors in Ship Design and Operation. 2011.

17. Lützhöft M, Dahlgren A, Kircher A, et al. Fatigue at sea in Swedish shipping: a field study. Am J Ind Med. 2010; 53(7): 733-740, doi: 10.1002/ajim.20814, indexed in Pubmed: 20187001.

18. Lin CT, Ko LW, Lin YH, et al. EEG activities of dynamic stimulation in VR driving motion simulator. Lecture Notes in Computer Science. Engineering Psychology and Cognitive Ergonomics. 2007: 551-560, doi: 10.1007/978-3-540-73331-7_60.

19. Singh R, Conjeti S, Banerjee R. A comparative evaluation of neural network classifiers for stress level analysis of automotive drivers using physiological signals. Biomedical Signal Processing and Control. 2013; 8(6): 740-754, doi: 10.1016/j.bspc.2013.06.014.

20. Whang MC, Lim JS, Park KR, et al. editors. Are Computers Capable of Understanding our emotional states? International Conference on Engineering Psychology and Cognitive Ergonomics. 2007: Springer.

21. Sharma N, Gedeon T. Objective measures, sensors and computational techniques for stress recognition and classification: a survey. Comput Methods Programs Biomed. 2012; 108(3): 1287-1301, doi: 10.1016/j.cmpb.2012.07.003, indexed in Pubmed: 22921417.

22. Slanzi G, Balazs J, Velásquez J. Combining eye tracking, pupil dilation and EEG analysis for predicting web users click intention. Information Fusion. 2017; 35: 51-57, doi: 10.1016/j.inffus.2016.09.003.

23. Zhu X. Zheng W-L, Lu B-L, Chen X, Chen S, Wang C, editors. EOG-based drowsiness detection using convolutional neural networks. IJCNN. 2014.

24. Chueh TH, Chen TB, Lu HS, et al. Statistical prediction of emotional states by physiological signals with manova and machine learning. International Journal of Pattern Recognition and Artificial Intelligence. 2012; 26(04): 1250008 , doi: 10.1142/s0218001412500085.

25. Brown I. Study into hours of work, fatigue and safety at sea. Medical Research Counsil, Cambridge. 1989.

26. Grech M, Horberry T, Humphreys M, editors. Fatigue and human error in the maritime domain. Proceedings of the 5th International Conference on Fatigue and Transportation: Coping with a 24 hour society; 2003: National Road Transport Commission.

27. Arulanandam S, Tsing GC. Comparison of alertness levels in ship crew. An experiment on rotating versus fixed watch schedules. Int Marit Health. 2009; 60(1-2): 6-9, indexed in Pubmed: 20205120.

28. Maurier P, Barnett M, Pekcan C, et al. Fatigue and Performance in Bridge and Engine Control Room Watchkeeping on a 6on/6off Watch Regime". Royal Institute of Naval Architects. 2011.

29. van Leeuwen WMA, Kircher A, Dahlgren A, et al. Sleep, sleepiness, and neurobehavioral performance while on watch in a simulated 4 hours on/8 hours off maritime watch system. Chronobiol Int. 2013; 30(9): 1108-1115, doi: 10.3109/07420528.2013.8008 74, indexed in Pubmed: 23879695.

30. Yilmaz H, Baźar E, Yúksekyildiz E. Investigation of Watchkeeping Officers' Watches Under The Working Hours Ineligible to STCW Regulation. TransNav, the International Journal on Marine Navigation and Safety of Sea Transportation. 2013; 7(4): 493-500, doi: 10.12716/1001.07.04.03.

31. Salyga J, Juozulynas A. Association between environment and psycho-emotional stress experienced at sea by Lithuanian and Latvian seamen. Medicina (Kaunas). 2006; 42(9): 759-769, indexed in Pubmed: 17028475.

32. Wadsworth EJK, Allen PH, Wellens BT, et al. Patterns of fatigue among seafarers during a tour of duty. Am J Ind Med. 2006; 49(10): 836-844, doi: 10.1002/ajim.20381, indexed in Pubmed: 16948149 . 
33. Lützhöft M, Grech M, Porathe T. Information Environment, Fatigue, and Culture in the Maritime Domain. Rev Hum Factors Ergonomics. 2011; 7(1): 280-322, doi: 10.1177/1557234×11410391.

34. Bal E, Arslan 0, Tavacioglu L. Prioritization of the causal factors of fatigue in seafarers and measurement of fatigue with the application of the Lactate Test. Safety Science. 2015; 72: 46-54, doi: 10.1016/j.ssci.2014.08.003.

35. Phillips R. Sleep, watchkeeping and accidents: a content analysis of incident at sea reports. Transportation Research Part F: Traffic Psychology and Behaviour. 2000; 3(4): 229-240, doi: 10.1016/ s1369-8478(01)00007-9.

36. Allen PH, Wellens BT, McNamara R, et al. It's not all plain sailing. Port turn-arounds and Seafarers' fatigue: A case study. 2005.

37. Mukhtar ZZ. A comparison of fatigue levels among Malaysian seafarers of different maritime sector. 2009.

38. Smith AP, Allen PH, Wadsworth EJK. Seafarer fatigue: The Cardiff research programme. 2006

39. Smith AP, Lane A, Bloor MJ, et al. Fatigue Offshore: Phase 2. The short sea and coastal shipping industry. 2003.

40. Ellis N, Bloor M, Sampson H. Patterns of seafarer injuries. Maritime Policy \& Management. 2010; 37(2): 121-128, doi: 10.1080/03088830903533742.

41. Jensen OC, S rensen JFL, Canals ML, et al. Incidence of self-reported occupational injuries in seafaring: an international study. Occup Med (Lond). 2004; 54(8): 548-555, doi: 10.1093/occmed/kqh090, indexed in Pubmed: 15385646.

42. Boucsein W, Haarmann A, Schaefer F. Combining skin conductance and heart rate variability for adaptive automation during simulated IFR flight. Lecture Notes in Computer Science. Engineering Psychology and Cognitive Ergonomics. 2007: 639-647, doi: 10.1007/9783-540-73331-7_70.

43. Groemer G, Gruber V, Bishop S, et al. Human performance data in a high workload environment during the simulated Mars expedition "AustroMars". Acta Astronautica. 2010; 66(5-6): 780-787, doi: 10.1016/j.actaastro.2009.08.017.

44. Tac U, Tavacioglu L, Bolat $P$, et al. Monitoring seafarers'cognitive performance under stressor factors during a voyage by automated neuropsychological assessment metrics. Universitatii Maritime Constanta Analele. 2013; 14(20): 291.

45. Lützhöft M, Sri TÅ. Fatigue Management Toolkit. 2012.

46. Sadock BJ, Sadock VA. Kaplan and Sadock's synopsis of psychiatry: Behavioral sciences/clinical psychiatry: Lippincott Williams \& Wilkins. 2011.
47. Kettunen J, Ravaja N, Näätänen $P$, et al. The synchronization of electrodermal activity and heart rate and its relationship to energetic arousal: a time series approach. Biol Psychol. 1998; 48(3): 209-225, indexed in Pubmed: 9788761.

48. Jacobs SC, Friedman R, Parker JD, et al. Use of skin conductance changes during mental stress testing as an index of autonomic arousal in cardiovascular research. Am Heart J. 1994; 128(6 Pt 1): 1170-1177, indexed in Pubmed: 7985598.

49. Healey JA, Picard RW. Detecting Stress During Real-World Driving Tasks Using Physiological Sensors. IEEE Transactions on Intelligent Transportation Systems. 2005; 6(2): 156-166, doi: 10.1109/tits.2005.848368.

50. Katsis CD, Katertsidis N, Ganiatsas G, et al. Toward emotion recognition in car-racing drivers: a biosignal processing approach. IEEE Transactions on Systems, Man, and Cybernetics - Part A: Systems and Humans. 2008; 38(3): 502-512, doi: 10.1109/ /tsmca.2008.918624.

51. Salahuddin L, Kim D. editors. Detection of acute stress by heart rate variability (HRV) using a prototype mobile ECG sensor. Proceedings of the International Conference on Hybrid Information Technology, Cheju Island, Korea. 2006.

52. Thayer RE. Activation states as assessed by verbal report and four psychophysiological variables. Psychophysiology. 1970; 7(1): 86-94, indexed in Pubmed: 5492738.

53. Lehto MR, Landry SJ. Introduction to human factors and ergonomics for engineers: Crc Press. 2012.

54. Madden DJ. Speed and timing of behavioral processes. Handbook of the psychology of aging. 2001; 5: 288-312.

55. Veasey S, Rosen R, Barzansky B, et al. Sleep loss and fatigue in residency training: a reappraisal. JAMA. 2002; 288(9): 1116-1124, indexed in Pubmed: 12204082.

56. Cattell RB. Factor analysis: an introduction and manual for the psychologist and social scientist. 1952.

57. Johnson R, Wichern D. Applied multivariate statistical analysis. PrenticeHall International. INC, New Jersey. 2007.

58. Hansen JH, Geving IH, Reinertsen RE. Adaptation rate of 6-sulfatoxymelatonin and cognitive performance in offshore fleet shift workers: a field study. Int Arch Occup Environ Health. 2010; 83(6): 607-615, doi: 10.1007/s00420-010-0547-x, indexed in Pubmed: 20499083.

59. Allen P, Wadsworth E, Smith A. Seafarers' fatigue: a review of the recent literature. Int Marit Health. 2008; 59(1-4): 81-92, indexed in Pubmed: 19227741.

60. Smith AP, Allen PH, Wadsworth EJ. Seafarers' fatigue: Conclusions and the way forward. Contemporary Ergonomics. 2008; 2008: 607. 